\title{
Shaping Concepts of Technology: What Concepts and How to Shape Them
}

\author{
MARC J. DE VRIES ${ }^{1}$ and ARLEY TAMIR ${ }^{2}$ \\ ${ }^{1}$ Eindhoven University of Technology, Eindhoven, The Netherlands; \\ ${ }^{2}$ Ministry of Education, Culture and Sports, Tel-Aviv, Israel
}

\begin{abstract}
Philosophy of technology is a discipline that has much to offer for technology education. Insights into the real nature of technology and its relationship with science and society can help technology educators to build a subject that helps pupils get a good concept of technology and to learn to understand and use concepts in technology. Here the way science educators have gained from the philosophy of science, for example in the idea of the way pupils learn concepts by reconstructing pre-concepts that they picked up from daily-life experiences. Research has shown that the learning of concepts and the learning of process skills have to be connected.
\end{abstract}

Keywords: concept learning, philosophy of technology, constructivism.

\section{THE IMPORTANCE OF TEACHING CONCEPTS IN TECHNOLOGY EDUCATION}

The main reason for the emergence of technology education as a key element in the education of all people is the importance of technology in our society. In the 'Agenda for future progress' that was presented at the end of JISTEC, it is stated that: 'The quality of life afforded by a society is directly and positively related to the extent to which people understand and effectively use existing technology, as well as creatively develop new technologies, while taking into account key scientific, economic, social and ecological aspects'. But in order to address the need for teaching technology for technological literacy in contemporary society, technology education must be more than the teaching and learning of handicraft skills, as was, and often still is, the case in classroom practice. Such education requires that pupils acquire an understanding of what technology is and how technological developments take place. It also means that a more theoretical component must be added to the practical dimension that already exists. In other words, not only skills, but also concepts of technology need to be taught and learnt. Here, we have to distinguish two levels: that of the overall concepts of the nature of technology ('concepts of technology') and a second level concerned with the theoretical concepts that are used in technological activity ('concepts in technology'). Both levels are discussed in this book, the aims of which are to show that the philosophy of technology has much to offer to technology education in terms of both of these types of concepts and that there are already some good examples of how technology educators draw upon them. Four themes have been covered, for each of which one or more chapters in the first part of the book (part A: philosophical perspectives) has a counterpart in the second (part B: mental images). These 
four themes are now discussed. In each case we first show the relevance of the philosophical papers that deal with it in part A, before turning to the educational contributions presented in part B.

THE POTENTIAL ROLE OF THE PHILOSOPHY OF TECHNOLOGY IN TECHNOLOGY EDUCATION

One of the issues technology educators face when making a transition from a craft, skills-oriented school activity to a new subject with a wider perspective on technology as a discipline and cultural phenomenon, is establishing the academic basis of this new subject. First thought suggests the various engineering disciplines, all of which show the general characteristics of technology. However these general characteristics are seldom made explicit in the engineering disciplines. As a result these disciplines can at best only offer part of the academic basis for technology education as a school subject. For the more general characteristics of technology and their explicit exploration, it is necessary to turn to the philosophy and methodology of technology. Curiously, it seems that the potential role of the philosophy and methodology of technology in technology education has only recently been discovered. One reason for this may be that the philosophy of technology cannot call upon a long tradition as a field of study. Although Mitcham, in his survey of the philosophy of technology (Mitcham, 1994) discusses some publications from the beginning of this century, the real rise of the philosophy of technology cannot be dated earlier than about the mid 1950s.

In this respect, the position of technology education is different from that, for example, of science education, where the academic basis is much clearer and the philosophy of science has been an established discipline for almost a century. Science educators have had the opportunity to benefit both from the academic sciences and the philosophy of science as a background for (further) developing their school subject (Willer, 1990). As an example, it has become evident from philosophical and methodological research that the growth of scientific knowledge is not a purely rational and linear process, and that non-rational, human factors play a vital role in it (Pickering's 1984 book Constructing Quarks is a well known example of research of this kind. Although less dramatic, Riordan's The Hunting of the Quark has the same kind of message, in that it shows the role of serendipity in science). Research into the nature of science and scientific activity has caused science educators to rethink the way they teach science, particularly when this teaching suggests the same sort of rationality and linearity that was previously considered to be a characteristic of science itself.

In technology education, parallel lessons can be learnt from the philosophy of technology. For example: in design methodology (which is often seen as a sub-discipline of engineering, but can also be developed as a sub-discipline of the philosophy of technology), it has been found that design 
processes cannot often be described adequately by linear process models. Nonetheless, in technology education such models are still widely used in teaching.

In general, one can say that philosophers seek answers to questions about the concepts to be shaped. In other words, what is a realistic concept of technology as a discipline and as a cultural phenomenon? What concepts constitute the knowledge base of technology? What are the processes in which these concepts are used to effect technological development? The challenge for technology educators is to find answers to the question of how the overall concept of technology and the concepts in technology are to be taught and learnt.

\section{THE NATURE OF TECHNOLOGY}

A first task for the philosopher of technology was, and is, to define the nature of technology. This is not an easy task, since technology is a very diffuse idea and many things are loosely referred to as technological. The question is, what are the general characteristics that determine when something can properly be called 'technology'?

One answer that was given previously, but is now no longer seen as adequate, is that technology is 'applied science'. Historically and methodologically, it can be shown that technological progression can only partially be accounted for by the use of scientific knowledge. Gardner in his chapter explores the example of the various parts of an overhead projector to show that the role of scientific knowledge in developing this device is limited. This example can be multiplied by many others. De Vries then further shows that there is a need to distinguish between different types of technologies, depending on the extent to which scientific knowledge contributes to the design of the products with which each is associated. The example of the Active Matrix Liquid Crystal Displays reveals what problems can occur when a manufacturing company does not take into account the fact that product development must accommodate the technology central to its success.

In education, we can also recognise the concept of technology as 'applied science', especially when technology itself is taught in the context of science education (Fensham \& Gardner, 1994). However this is only one of the misconceptions widely held about technology. Research, in particular in the international series of PATT studies (PATT $=$ Pupils' Attitudes Towards Technology) has shown how pupils who have had no exposure to technology education usually think about technology only in terms of products and do not recognise it as a process (De Klerk Wolters, Raat \& De Vries, 1990). Jones in his chapter presents a survey of the various research studies into the concepts of technology held by pupils. Thomson presents one particular way of doing such research, namely by using concept mapping. Her results shows that changing a school curriculum can change pupils' 
concepts of technology. As a consequence, technology educators should think carefully about what concept of technology they want the pupils' to acquire and then see if their curriculum, through all the various activities it comprises, is supportive of it.

\section{RATIONAL AND NON-RATIONAL FACTORS IN TECHNOLOGICAL DEVELOPMENTS}

Another widely held idea about the nature of technology, but one that is now questioned, is the assumed dominance of rationality in technological development. By a careful philosophical analysis of the idea of rationality in science and technology, Agassi in his chapter makes us aware of the limitations of the role which rationality can play. Far more than was admitted in the past, non-rational factors influence decision-making in the development both of new knowledge and of new products and processes. This, of course, illustrates how much technology is truly a human affair.

Hansen, in his chapter, complains about the fact that policy makers often try to diminish the role of technology education in the curriculum by questioning its value in terms of rationality. He challenged this in the subtitle of his JISTEC conference paper: What if schooling were based on a different set of premises (i.e. different from a purely rational set of premises)? He makes a plea for learning technology through experiences which embrace rational and non-rational aspects, and which, just like technology itself, highlights not only reasoning, but also 'instinct'. Such experiences would do more justice to the learning of technology as a truly human affair.

\section{CONSTRUCTING AND RECONSTRUCTING CONCEPTS}

The way rational and non-rational factors function in specific technological developments is studied in the academic field of technology dynamics, to which philosophers, historians and sociologists contribute. A growing number of case studies show how various actors influence the extent to which a technological invention becomes a success or a failure. Some scholars even claim that technological innovations can be almost totally described as 'social constructs' (Bijker, 1992). Others do not want to go this far and emphasise the role of the level in the hierarchy of the technical system being studied. As Vincenti (1992) writes: 'An airplane is as much a social construct as it is a technical; its landing gear and landing-gear components are not'. What he means to say is that the more the technological development is at the level of detail, the less social actors exert an influence. In this sense, not all technological inventions can be described as 'social constructs'. The philosophy of this so-called social constructivism is discussed in K.-H. Hansen's chapter, where he presents a balanced view 
that acknowledges the value of social constructivism while recognising its limitations. Whatever its values and weaknesses may be, social constructivism is certainly a key issue in the sociology and philosophy of technology today.

Science education has for several years already drawn parallels between social constructivism in sociology and philosophy and the teaching and learning of science. We have already referred to Pickering's book on quarks. More recent science education projects and curricula all pay considerable attention to social aspects in teaching about the growth of scientific knowledge. There is also a second level of educational research in science education for which the term 'constructivism' is used. This relates to how learners acquire scientific concepts. Several studies in various areas of science (e.g. optics, mechanics and electricity) have shown that learning concepts can be seen as a reconstruction of existing concepts that pupils have already acquired before they enter the science lesson. Often these concepts conflict with scientific concepts and a first step towards reconstructing them in pupils' minds involves making these conflicts explicit by confronting them with the outcomes of experiments that they do themselves or observe as they are demonstrated to them. In technology education, we have not yet done much to establish pupils' preconceptions with regard to specific technological concepts (like 'systems'). What is their 'natural' view on e.g. a washing machine, and how does this sit alongside the way the engineers describe it as a system with inputs, processes and outputs? We have not even started yet to search for an answer to such questions. In her chapter, Hill discusses the relevance of constructivism (or as she calls it 'constructionism') to technology education. Here there is certainly much to be gained from the research methodology that has been built up over many years in science education.

\section{THE RELATIONSHIP BETWEEN CONCEPTS AND PROCESSES}

Acknowledging the role of non-rational factors in technology does not involve denying that theoretical concepts also have a vital role. Philosophical investigation into such concepts is quite recent. In other words, the epistemology of technology is by no means yet a fully developed area. However, it is already clear that conceptual knowledge is an essential component in technological design and problem solving processes. Studies in design methodology have shown that design processes combine knowledge about concepts (declarative knowledge) and process knowledge (such as procedural, situational and strategic knowledge) (Christiaans \& Dorst, 1992). Ropohl in an epistemological survey in his chapter in this book elaborates the content of the various types of conceptual (or 'technological') and procedural (or 'technical') knowledge that engineers use. In addition he shows that an understanding of our technological world is also a necessary component of technological knowledge. 
For education, this means that the teaching and learning of design and technological problem solving can never be separated from the teaching and learning of technological concepts. McCormick draws upon his research in this area to question the whole idea of teaching design problem solving as a general skill. As a minimum there is always a situational aspect in design and problem solving activities that must be taken into account. If this is not done, pupils will not be able to find their way through the problem. Even so, as Johnson shows in his chapter, the learning of general concepts and skills is necessary because of the rapid changes in technology: the more specific the knowledge and skills that are taught, the sooner they will become outdated and old fashioned. In consequence, it is necessary to search for ways in which general concepts and skills can be taught and learnt, and within which concepts and skills are essentially related to each other and to the specific situation in which they are applied. This most certainly is an important challenge for teacher training programmes.

\section{TRANSFORMING CONCEPTS FROM SCIENCE TO TECHNOLOGY}

We have already seen that the paradigm of 'technology as applied science' is no longer seen as a valid description of the nature of technology. Looking at the level of specific concepts within technology, we revisit this issue to look at it from a different perspective. Epistemological studies have shown that even where scientific concepts are used in technology, this is not done in a straight forward way. Vincenti (1990) has described the example of 'control volume' as an example of how a theoretical scientific concept has to be transformed to a more practical concept in order to be usable by engineers. Often there is a gap between an idealised theory in science and the practice of engineering. Engineers never deal with e.g. ideal gases, frictionless situations, point masses and similar idealisations as scientists do in their theories. They need therefore what might be called intermediate concepts which make a bridge between the concrete reality of design and the idealised concepts drawn from science. Scientific concepts are thus transformed in the process of designing. The opposite is also possible, as Ihde illustrates in his chapter: technology is a medium through which scientists draw their concepts from reality, transforming them thereby. Ihde illustrates his case by using examples from optical instrumentation.

Since designers and engineers transform concepts from science to make them usable for themselves, this is also likely to be the case in technology education, where scientific concepts are used in certain design activities. This transformation is therefore a complicating factor for establishing relationships between science education and technology education. It means that the concepts pupils learn in science education cannot immediately be used in technology education, but may need to be reworked and transformed. Similarly, when technology educators want to use concepts that are used in engineering, those concepts too may need a transformation. Examples 
of this are presented by Durey for the areas of CAD/CAM and electronics teaching. From his chapter, it becomes evident that while such transformations are possible, they are not without problems.

\section{CONCLUDING REMARKS}

From the various chapters in this book, it will become evident to the reader that shaping and re-shaping concepts of, and in technology, is an area that has just begun to be explored. What is the way forward? What needs to be done in terms of research and development work? What can we expect to be the value of this area for the further development of technology education in conjunction with the philosophy and methodology of technology?

In the closing session of JISTEC, from which this book originates, a research agenda was presented as part of the "Agenda for further progress', from which we quoted at the beginning of this chapter. In that research agenda, there are several points that relate to the theme of this book. We focus on two issues.

First we think that there is a need for further contact and dialogue between philosophers of technology and technology educators in order to conceptualise technology education, its relationship with other disciplines and its impact on society and culture. As noted in the Preface, this book is one of the first to bring together contributions from those two fields of activity. A reader like 'Technology for Technology Education' (McCormick, Newey $\&$ Sparkes, 1993) touches some of the issues that are discussed in our book, but from a more practical perspective. In those institutions that have both technology education and STS programmes on campus, the opportunities for cooperation are particularly great. STS is the acronym for Science, Technology and Society. This is the term that has become a common descriptor for academic programmes that combine subjects in science, engineering and social sciences (De Vries, 1994). Such programmes usually have a philosophical and/or sociological component that is worth exploring for technology educators. This type of cooperation could be meaningful for technology educators seeking general concepts that are to be taught and learnt in technology education. Such concepts are increasingly explored by technology educators - Blandow (1993) is good an example of how far one can go into this - but the basis for such concepts now remains more prescriptive than descriptive (in other words, the concepts are elaborated in theory, but do not always have empirical evidence to support them).

Secondly, we see a need for more research in the areas of pupils' and students' preconceptions of technological concepts and the way in which these can be influenced by real or simulated educational experiences with technological activities. The effectiveness of technology education programmes in terms of assessing how pupils' concepts have changed has so far been included in very few research projects. Closely related to this is the need for research into how teachers can be prepared to guide design 
and problem solving activities in which such concepts are linked with processes. The number of institutions involved in this kind of research remains small, especially from a global perspective. It would be worth exploring the feasibility of carrying out an international research agenda like to one proposed by Jenkins (1992). The International Journal of Technology and Design Education is a readily available medium for publishing the outcomes of studies derived from such an agenda.

\section{REFERENCES}

Bijker, W. E.: 1992, 'The Social Construction of Fluorescent Lighting, or How an Artifact Was Invented in Its Diffusion Stage', in W. E. Bijker \& J. Law (eds.), Shaping Technology/Building Society. Studies in Sociotechnical Change, The MIT Press, London and Massachusetts, 75-104.

Blandow, D.: 1993, 'Innovation and Design for Developing Technological Capabilities in General Education', in M. J. de Vries, N. Cross \& D. P. Grant (eds.), Design Methodology and Relationships with Science, Kluwer Academic Publ., Dordrecht, 277-308.

Christiaans, H. \& Dorst, K.: 1992, 'An Empirical Study into Design Thinking', in N. Cross, K. Dorst \& N. Roozenburg (eds.), Research in Design Thinking, Delft University Press, Delft, 119-126.

Fensham, P. J. \& Gardner, P. L.: 1994, 'Technology Education and Science Education: A New Relationship?', in D. Layton (ed.), Innovations in Science and Technology Education, Vol. V, UNESCO, Paris, 159-170.

Jenkins, E. W.: 1992, 'Towards an Agenda for Research in Technology Education', in D. Blandow \& M. J. Dyrenfurth (eds.), Technological Literacy, Competence and Innovation in Human Resource Development. Proceedings of the First International Conference on Technology Education, WOCATE/AEA, Erfurt/Columbia, 458-462.

Klerk Wolters, F. De, Raat, J. H. \& Vries, M. J. de: 1990, 'Assessing Students' Attitudes towards Technology', in D. Layton (ed.), Innovations in Science and Technology Education, Vol. III, UNESCO, Paris, 111-121.

Mitcham, C.: 1994, Thinking through Technology. The Path between Engineering and Philosophy, The University of Chicago Press, Chicago/London.

McCormick, R., Newey, C. \& Sparkes, J (eds.): 1993, Technology for Technology Education, Addison-Wesley Publ. Comp., Wokingham.

Pickering, A.: 1984, Constructing Quarks. A Sociological History of Particle Physics, The University of Chicago Press, Chicago.

Riordan, M.: 1987, The Hunting of the Quark. A True Story of Modern Physics, Simon \& Schuster, Inc., New York.

Vincenti, W. G.: 1990, What Engineers Know and How They Know It. Analytical Studies from Aeronautical History, The John Hopkins University Press, Baltimore and London.

Vincenti, W. G.: 1992, 'Engineering Knowledge, Type of Design, and Level of Hierarchy: Further Thoughts about What Engineers Know . . .', in P. A. Kroes \& M. Bakker (eds.), Technological Development and Science in the Industrial Age. New Perspectives on the Science-Technology Relationship, Kluwer Academic Publishers, Dordrecht, 17-34.

Vries, M. J. de: 1994, 'Design Methodology in Academic STS Programs', in D. \& K. Cheek (eds.), Proceedings of the Nineth National Technology Literacy Conference, ERIC Clearinghouse for Social Studies/Social Sciences Education, 142-149.

Willer, J.: 1990, Physik und menschliche Bildung. Eine Geschichte der Physik und ihres Unterrichts, Wissenschaftliche Buchgesellschaft, Darmstadt. 